\title{
Synthesis and Characterization of Poly Anthranilic Acid Metal Nanocomposites
}

\author{
Irudaya Antonat Sophia ${ }^{1}$, G. Gopu ${ }^{2}$, C. Vedhi ${ }^{\text {* }}$ \\ ${ }^{1}$ Department of Chemistry, V. O. Chidambaram College, Thoothukudi, India \\ ${ }^{2}$ Department of Industrial Chemistry, Alagappa University, Karaikudi, India \\ Email: *cvedhi@rediffmail.com, iasophiaraja@gmail.com
}

Received March 1, 2012; revised April 3, 2012; accepted April 11, 2012

\begin{abstract}
Intrinsically conducting polymer metal nanocomposites were synthesized by polymerising anthranilic acid (PANA) with metal salts like ferric chloride, Zinc oxide and Magnesium oxide by chemical oxidation method. Polyanthranilic acid-iron nano composite (PANA-Fe), Polyanthranilic acid-Zinc nano composite(PANA-Zn) and Polyanthranilic acidmagnesium nano composite (PANA-Mg) synthesized were characterised by UV-Visible and FTIR studies. FTIR spectra of polymer-metal nano composites showed peaks in the region between $1690 \mathrm{~cm}^{-1}$ and $1490 \mathrm{~cm}^{-1}$ which corresponds to the deformation in different types of $\mathrm{N}-\mathrm{H}$ bond. The participation of the - $\mathrm{NH}$ group in polymerization was confirmed by the appearance of a peak around $3431 \mathrm{~cm}^{-1}$. Cyclic voltammetric studies revealed the presence of an adherent polymer film on the glassy carbon electrode and showed redox behavior of the polymer metal nanocomposites. The XRD (XRay Diffraction) studies showed a rather more crystalline behaviour of the nano composites and the grain size was calculated using Scherrer's formula and it was found to be in nano range. SEM (Scanning Electron Microscope) analysis showed a rather mixed crystalline and amorphous behavior. EDAX (Energy Dispersive X Ray Spectroscopy) confirms the incorporation of the metals iron, Zinc and Magnesium in the polymer-metal nano composites. The inhibition efficiency of the polymer-metal nano composites were calculated for stainless steel in acidic environment using electrochemical impedance spectroscopy (EIS) and polarization (Tafel) studies and the prepared PANA-Fe and PANA-Zn nano composites showed effective anti-corrosive behavior on stainless steel in acid medium.
\end{abstract}

Keywords: Poly Anthranilic Acid; Polymer Metal Nanocomposites; Cyclic Voltammetry; EIS; SEM; TEM

\section{Introduction}

For the past few decades polyanilines and substituted polyanilines have emerged as efficient class of corrosion inhibitors for mild steel (MS) and stainless steel (SS) in acidic media. The passivation of the metal surface is responsible for the protective activity of polyaniline and substituted polyanilines [1]. This was elucidated with potential and polarisation measurements on stainless steel. The general observation is that there is a significant potential shift towards more noble values and an increase of the polarisation resistance takes place [2,3]. Intrinsically conducting polymers definitely possess promising potential for application in intelligent corrosion protection coatings. Incorporation of metals and metal oxides in intrinsically conducting polymers (ICP) can enhance electron transfer through a direct or mediated mechanism with improved conductivity and enhanced stability. It has been reported earlier that the formation of pitting corrosion $[4,5]$ is inhibited by the application of conducting

${ }^{*}$ Corresponding author. polymers on SS surface. The protective behaviour of conducting and insulating forms of polymers on SS has also been reported earlier [1,6]. Insulating coatings act as a barrier against diffusion to polymer/metal interface of corrosive ions but conducting polymer coatings stabilize the metal within the potential range of the passive region.

Synthesis and characterization of sulfonated polyanilines has been dealt with extensively in literature, but only few papers pay attention to their parent carboxylated derivatives [7-16]. Moreover, most of these reports are limited to the study of the copolymers formed by either chemical or electrochemical polymerization of aniline and substituted aniline with o-amino benzoic acid (anthranilic acid) $[7,8,10,12,16]$. A comparison between the homopolymers synthesized electrochemically from ortho, meta and p-aminobenzoicacids was reported for the first time by Thiemann and Brett [13,14]. The preparation of a poly (anthranilic acid)-palladium nanoparticle composite material by polymerization of anthranilic acid (AA) monomer using palladium acetate (PA) as the oxidant had been already carried out earlier [17]. Poly (anthranilic 
acid) was first reported as a self doped conducting polymer and an efficient corrosion inhibitor for mild steel in acidic solution [18] by Sudhish Kumar Shukla et al.

The aim of this work is to prepare poly (o-aminobenzoicacid) metal nano composites (metals introduced were Zinc, Magnesium and iron) and study their electrochemical and corrosion behavior on SS.

\section{Experimental}

\subsection{Materials}

o-aminobenzoic acid (Aldrich), hydrochloric acid, potassium per sulphate, ferric chloride, zinc oxide and magnesium oxide were used as such.

\subsection{Synthesis of Poly (Anthranilic Acid) —-Iron Nano Composite}

Anthranilic acid and ferric chloride was taken in the ratio of 1:2. Ferric chloride itself acted as an oxidant. The monomer was dissolved in $0.1 \mathrm{M}$ hydrochloric acid and a suitable amount of aqueous solution of ferric chloride was added slowly into the monomer. The solution was kept stirring for about $3.0 \mathrm{~h}$ at room temperature, it was then left overnight in the refrigerator, after which the brownish black powder obtained was filtered, dried and was found to be soluble in dimethyl sulphoxide, N-methyl pyrrolidine, diethylene glycol and sodium hydroxide to give reddish brown solutions.

\subsection{Synthesis of Poly (Anthranilic Acid)—Zinc Nano Composite}

Anthranilic acid (monomer), potassium per sulphate (oxidant) and zinc oxide were taken in the ratio of 1:2:1. The monomer was dissolved in $0.1 \mathrm{M}$ hydrochloric acid and the aqueous solution of the oxidising agent was slowly added into monomer and metal salt solution. The solution was kept stirring for about $3.0 \mathrm{~h}$ at room temperature, it was then left overnight in the refrigerator, after which the brownish black powder obtained was filtered, dried and was found to be soluble in dimethyl sulphoxide, N-methyl pyrrolidine, diethylene glycol and sodium hydroxide to give reddish brown solutions.

\subsection{Synthesis of Poly (Anthranilic Acid)-Magnesium Nano Composite}

The same procedure was followed as done for Poly (Anthranilic Acid) - magnesium Nano Composite using magnesium oxide.

\subsection{Characterizations}

The solution of the polymer metal nano composites in dimethyl sulphoxide was used for recording the UV-VIS spectra. For recording the UV-Vis absorption spectra, a computer controlled JascoV-500 spectrophotometer was used. The FT-IR spectra were recorded using a SHIMADZU instrument. The X-ray diffraction (XRD) patterns were recorded for the powdered materials using a BRUKER (D8 ADVANCE) X-ray diffractometer. The polarization and impedance studies were carried out using electrochemical workstation (mode 650C), CH-Instrument Inc., TX, USA. The polarization measurements were carried out from cathodic potential of $-0.7 \mathrm{~V}$ vs. $\mathrm{Ag} / \mathrm{Ag}^{+}$to an anodic potential of $+0.7 \mathrm{~V}$ vs. $\mathrm{Ag} / \mathrm{Ag}^{+}$with respect to the open circuit potential at a sweep rate 50 $\mathrm{mV} \cdot \mathrm{s}^{-1}$ to study the effect of inhibitor on stainless steel corrosion. The electrochemical studies were carried out in a three electrode cell $[19,20]$. Pt was used as counter electrode and silver-silver chloride electrode as reference electrode. In the case of cyclic voltammetric studies the polymer and the metal polymer nano composites were coated on a glassy carbon electrode by dissolving a pinch of the polymer sample in DMSO. For impedance studies the stainless steel strip was used as the working electrode and it was embedded in araldite, so as to expose a surface area of $1.0 \mathrm{~cm}^{2}$. The electrode was polished successively on the emery paper and then degreased with trichloroethylene.

The charge transfer resistance was obtained from the diameter of the semi circles of the Nyquist plots. The inhibition efficiency of the inhibitor was calculated from the charge transfer resistance values using the following equation [18]

$$
\mathrm{I} . \mathrm{E} \%=\left(R_{c t}-R_{c t}^{0}\right) 100 / R_{c t}
$$

where $R_{c t}^{0}$ and $R_{c t}$ are the charge transfer resistance in the absence and presence of inhibitor.

The surface coverage values $(\theta)$ were calculated from the $C_{d l}$ values according to the equation [18].

$$
\text { Surface coverage }(\theta)=\left(C_{d l}-C_{d l(i)}\right) / C_{d l}
$$

The corrosion inhibition efficiency from the polarization studies (I.E\%) was evaluated from the measured $I_{\text {corr }}$ values using the relationship[18]:

$$
\mathrm{I} . \mathrm{E} \%=\left(I_{\text {corr }}^{0}-I_{\text {corr }}\right) 100 / I_{\text {corr }}^{0}
$$

where $I_{\text {corr }}^{0}$ and $I_{\text {corr }}$ are the corrosion current densities in absence and in presence of the inhibitor.

\section{Results and Discussion}

\subsection{UV-VIS Studies}

UV-VIS spectra of Poly(o-amino benzoic acid) exhibits three bands around $272 \mathrm{~nm}, 375 \mathrm{~nm}$ and $562 \mathrm{~nm}$ as shown in Figure 1. The first (shoulder) about at $272 \mathrm{~nm}$ is attributed to the JI-JI* transition for the benzenoid ring, the band at $375 \mathrm{~nm}$ for quinoid rings and $562 \mathrm{~nm}$ for 


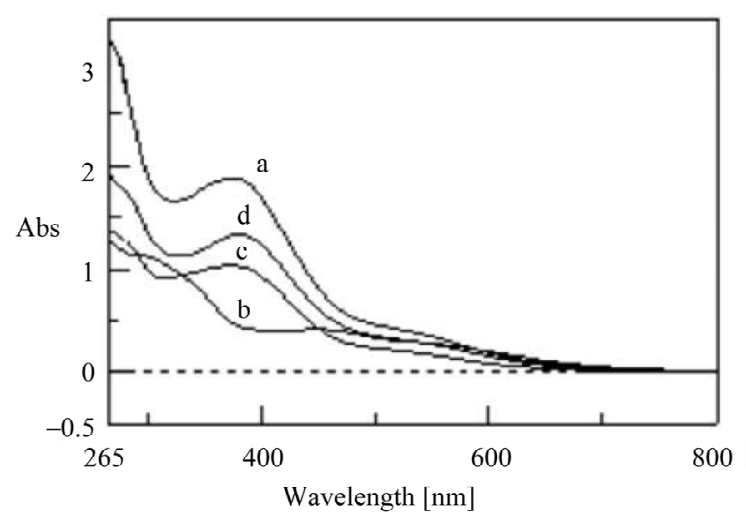

Figure 1. UV-VIS spectra of (a) PANA; (b) PANA-Fe; (c) PANA-Zn; (d) PANA-Mg nanocomposites.

polaronic transition due to the emeraldine state of the polymer. This is in agreement with the results reported earlier [18]. Introduction of the metals (iron, Zinc and Magnesium) showed a slight hypsochromic shift in the bands.

When Zinc is introduced, hypsochromic shift is observed with peaks at $261 \mathrm{~nm}, 373 \mathrm{~nm}$ and at $570 \mathrm{~nm}$. In the case of iron added composites also hypsochromic shift is observed with peaks at $262 \mathrm{~nm}, 368 \mathrm{~nm}$ and 565 $\mathrm{nm}$, the shift is expected due to less conjugation along the polymeric chain and the steric effect of the bulky $\mathrm{COOH}$ group and the incorporated metal into the polymeric matrix. In the case of magnesium included composites the peaks appeared at $266 \mathrm{~nm}, 372 \mathrm{~nm}$ and 565 nm.

\subsection{FTIR Studies}

The FTIR spectra as shown in Figure 2 shows the following bands for poly (anthranilic acid) namely a band at $3431 \mathrm{~cm}^{-1}$ (N-H stretching), $2615 \mathrm{~cm}^{-1}$ (O-H stretching), $1691 \mathrm{~cm}^{-1}(\mathrm{C}=\mathrm{O}), 1558 \mathrm{~cm}^{-1}$ (quinoid $\mathrm{C}=\mathrm{C}$ stretching), $1506 \mathrm{~cm}^{-1}$ (benzenoid $\mathrm{C}=\mathrm{C}$ stretching), $1450 \mathrm{~cm}^{-1}$ (stretching of aromatic ring), $1373 \mathrm{~cm}^{-1}$ (C-N stretching for secondary aromatic amine), $1247 \mathrm{~cm}^{-1}$ ( C-H stretching), $1166 \mathrm{~cm}^{-1}(\mathrm{~N}=\mathrm{Q}=\mathrm{N}$ stretching $\mathrm{Q}=$ quinoid ring $), 1081$ $\mathrm{cm}^{-1}$ and $1045 \mathrm{~cm}^{-1}$ (aromatic $\mathrm{C}-\mathrm{H}$ in plane bending), $821 \mathrm{~cm}^{-1}$ and $756 \mathrm{~cm}^{-1} \mathrm{C}-\mathrm{H}$ out of plane bending and confirms 1,4 disubstituted benzene ring). This result is similar to the one published by Rao and Sathyanarayana. Yan et al. who had similar observations from X-ray photon spectroscopy for poly (2-aminobenzoic acid) [12].

Introduction of iron into the polymeric chain causes an increase in the O-H stretching from 2615 to $2854 \mathrm{~cm}^{-1}$. Appearance of additional bands around $675 \mathrm{~cm}^{-1}$ confirms the metal stretching (Further confirmed by EDAX). In the case of PANA-Zn and PANA-Mg the bands were almost similar to PANA indicating the absence of any kind of chemical interaction between the polymer and the

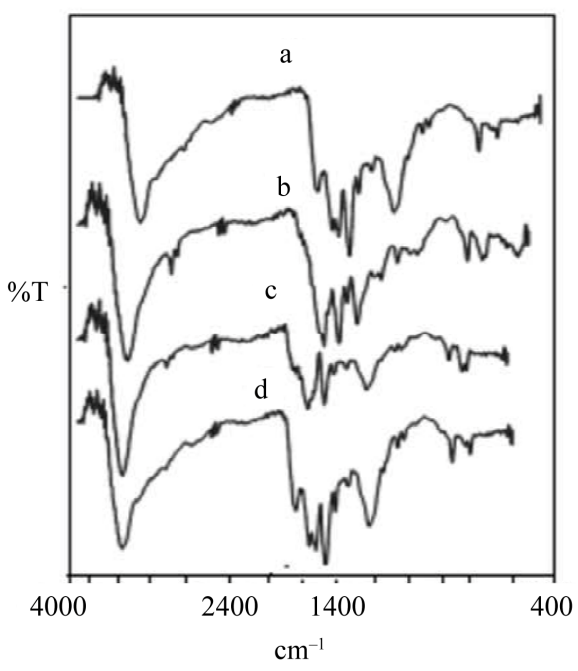

Figure 2. FTIR behaviour of (a) PANA; (b) PANA-Fe; (c) PANA-Zn; (d) PANA-Mg nanocomposites.

metal.

\subsection{Cyclic Voltammogram Behaviour of Polymer Metal Nano Composites}

Cyclic voltammogram of PANA and its metal nano composites were recorded by cycling the potential between $-0.2 \mathrm{~V}$ and $1.2 \mathrm{~V}$ in $0.1 \mathrm{~N} \mathrm{HCl}$ as shown in Figure 3 . Here appeared one anodic and a broad cathodic peak for polymer. Similarly metal introduced composites also exhibited anodic and cathodic peaks but potential of peaks is different from polymer this might be due to incorporation of metal ions. As the scan rate increases the peak current of polymer and polymer metal composites also increased linearly, it is indicating an adherent film on the glassy carbon electrode, this was further confirmed by a straight line graph obtained by plotting peak current Vs scan rate as presented in Figure 4.

\subsection{EIS and Polarisation Studies}

Electrochemical impedance measurements were carried over a frequency range from $1000 \mathrm{~Hz}$ to $0.01 \mathrm{~Hz}$ at open circuit potential. The simple equivalent Randle circuit for studies is given in Figure 5. The presence of a single semi circle (Figure 6) shows the coating acts as a barrier. It is seen that introduction of metal atom increases the values of $R_{c t}$ and reduces the $C_{d l}$. The charge transfer resistance $\left(R_{c t}\right)$ value for bare $\mathrm{SS}$ is low $\left(40 \Omega \mathrm{cm}^{2}\right)$, whereas for the metal polymer nano composites it is high. Also the decrease in $C_{d l}$ is attributed to increase in thickness of electronic double layer [19]. The increase in $R_{c t}$ value is attributed to the formation of protective film on the metal/solution interface. These observations suggest that metal PANA composites function by adsorption at metal surface thereby causing the decrease in $C_{d l}$ values 


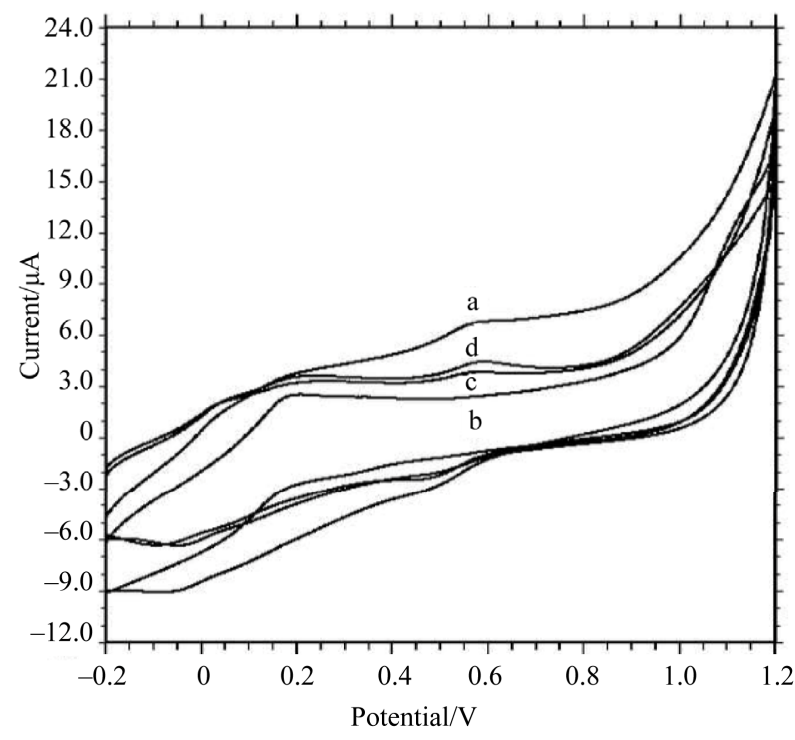

Figure 3. Cyclic voltammogram of (a) PANA; (b) PANA-Fe; (c) PANA-Zn; (d) PANA-Mg.

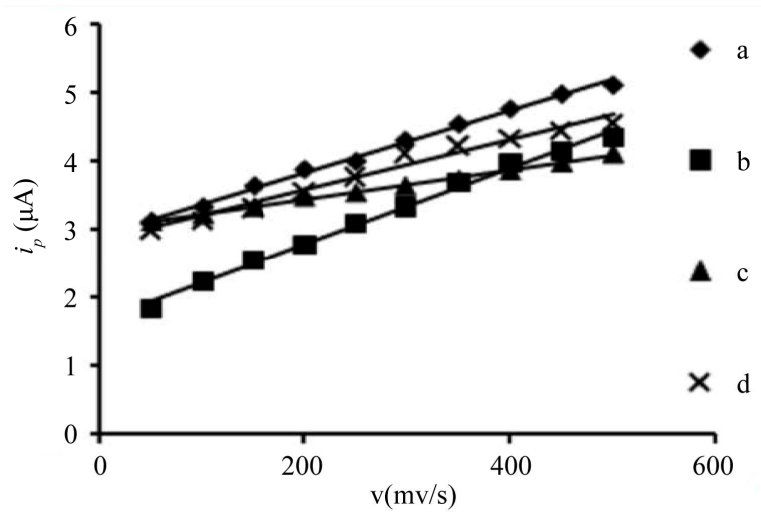

Figure 4. Plot of peak current Vs scan rate.

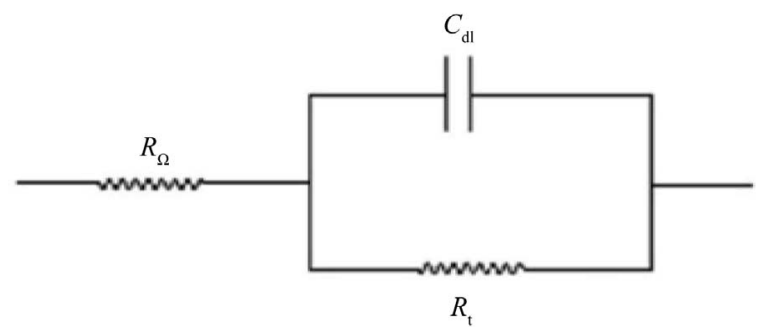

Figure 5. Electrical equivalent circuit.

and increase in $R_{c t}$ values. The charge transfer resistance $\left(R_{c t}\right)$ and the interfacial double layer capacitance $\left(C_{d l}\right)$ derived from these curves are given in Table 1. From the table it is clear that the $R_{c t}$ value increases gradually and is maximum for PANA-Zn indicating that the PANA-Zn film imposes a certain inhibition to the corrosion process of the steel and then comes PANA-Fe. The inhibitor efficiency for PANA- Mg and the polymer without the metal is the same indicating that this metal composite is not a

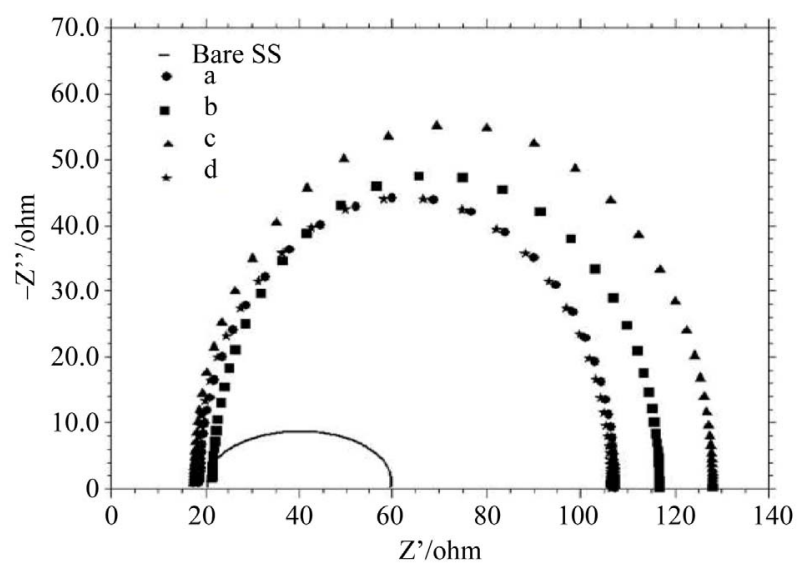

Figure 6. Electrochemical Impedance spectra of (a) PANA; (b) PANA-Fe; (c) PANA-Zn; (d) PANA-Mg.

Table 1. $\boldsymbol{R}_{c t}, C_{d l}$, I.E\% and Surface Coverage $(\theta)$ for PANA, PANA-Zn, PANA-Fe and PANA-Mg.

\begin{tabular}{ccccc}
\hline polymer & $\boldsymbol{R}_{\mathrm{ct}}\left(\mathbf{\Omega c m}^{2}\right)$ & $\boldsymbol{C}_{\mathrm{dl}}\left(\boldsymbol{\mu} \mathbf{F c m}{ }^{-2}\right)$ & $\mathbf{I . E \%}$ & $\boldsymbol{\theta}$ \\
\hline Blank & 40.00 & 211.1 & - & - \\
PANA & 88.56 & 161.7 & 54.83 & 0.23 \\
PANA-Fe & 95.22 & 103.0 & 57.99 & 0.51 \\
PANA-Zn & 110.50 & 100.2 & 63.80 & 0.53 \\
PANA-Mg & 88.50 & 201.5 & 54.80 & 0.05 \\
\hline
\end{tabular}

good inhibitor. The surface coverage value $(\theta)$ also is higher in the case of Zinc when compared to Fe.

\subsection{Polarisation Studies}

The polarisation behavior of SS in $1.0 \mathrm{M} \mathrm{HCl}$ without metal and with metal is shown in Table 2. Tafel curves show that the protective action of the polymer metal composite promotes a change of the corrosion potential to more positive values for stainless steel coated with PANA-Zn and PANA-Fe. The observations of the present results pointed out the remarkable capability of PANI-Zn and PANA-Fe to protect steel against corrosion in $1.0 \mathrm{M} \mathrm{HCl}$ solutions. By comparison, it can be found that the EIS data are consistent with the Tafel curves of each PANA film-covered stainless steel electrode in Figure 7.

\subsection{XRD Behaviors of Polymer and Polymer Metal Nano Composites}

The X-ray powder diffraction patterns for the polymers of o-amino benzoic acid as in Figure 6 are typical of semi crystalline polymers. Polymers with high crystallinity usually show higher conductivity. The particle size was calculated using Scherrer equation [20]. In the case of the polymer metal nano composites the particle size was $2.0 \mathrm{~nm}$. On introducing the metals the particle size 
Table 2. Polarization data for polymer and metal polymer nano composites.

\begin{tabular}{cccc}
\hline polymer & $\boldsymbol{E}_{\text {corr }}$ & $\boldsymbol{I}_{\text {corr }}$ & I.E\% \\
\hline Blank & -0.3247 & 19.27 & - \\
PANA & -0.1077 & 15.95 & 17.23 \\
PANA-Fe & -0.0817 & 12.15 & 36.95 \\
PANA-Zn & -0.0220 & 10.05 & 47.85 \\
PANA-Mg & -0.0980 & 15.18 & 21.22 \\
\hline
\end{tabular}

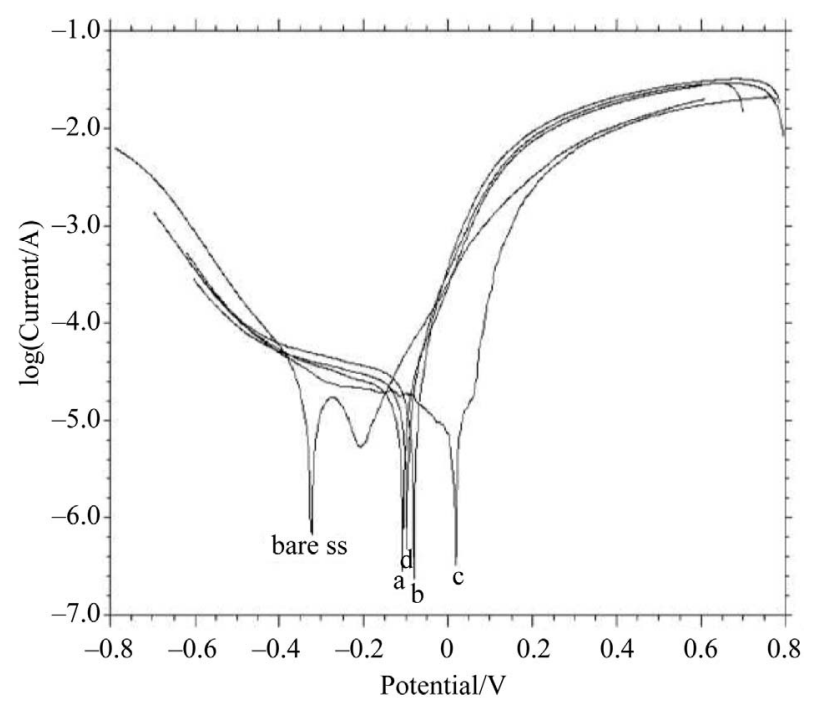

Figure 7. Tafel plot for (a) PANA; (b) PANA-Fe; (c) PANAZn; (d) PANA-Mg.

of the nano composites gradually increased. XRD pattern as shown in Figure 8 shows a broad peak for PANA, in the case of polymer metal composites the peaks are rather sharp indicating more crystallinity and hence more conductivity.

\subsection{SEM and EDAX Behaviours of Polymer and Polymer Metal Nano Composites}

The SEM micrographs were used to investigate the morphology of the polymer and metal polymer nano composites. Polyanthranilic acid displays spherical shaped structures (Figure 9). PANA-Fe shows an agglomerated structure. The polymer metal nanocomposites especially the PANA-Zn and PANA-Mg exhibits mixed granular and agglomerates morphology which may result from intramolecularly hydrogen bonded amino benzoic acid units [21].

EDAX confirms the incorporation of $\mathrm{Fe}, \mathrm{Zn}$ and $\mathrm{Mg}$ into the polymer matrix as shown in Figure 9. Sharp intense peaks were obtained in the case of PANA-Fe composite. In the case of PANA-Zn composite, though the peak for $\mathrm{Zn}$ was less intense, the incorporated $\mathrm{Zn}$ provided better inhibition on SS. As far as PANA Mg

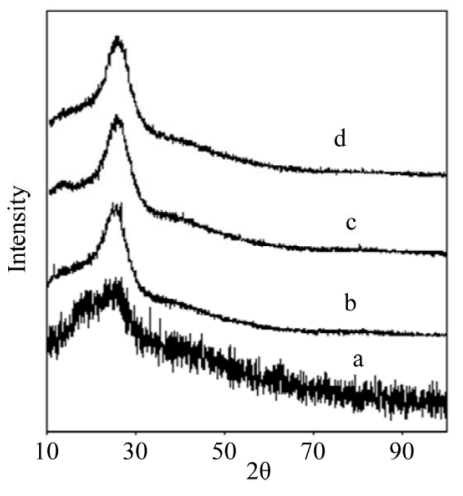

Figure 8. XRD of (a) PANA; (b) PANA-Fe; (c) PANA-Zn; (d) PANA-Mg.

composite is concerned, the peak due to $\mathrm{Mg}$ is very weak and its inhibition property is also almost similar to the PANA as revealed from EIS and polarization studies.

\subsection{TGA/DTA}

The weight loss patterns in Figure $\mathbf{1 0}$ are in good agreement with previous reports on polyaniline. The TGA curve for PANA showed a rapid decomposition from about 100 until about $800^{\circ} \mathrm{C}$. DTA curves showed endothermic peaks around $95^{\circ} \mathrm{C}$, while exothermic peaks were observed.

The first weight loss observed around is $125^{\circ} \mathrm{C}$ and $250^{\circ} \mathrm{C}$ due to loss of moisture, the second weight loss is due to the removal of dopants and the weight loss after $295.64^{\circ} \mathrm{C}$ corresponds to the decomposition of the polymer [22-25]. In the case of PANA-Fe, the polymer metal nanocomposite is stable up to $664.46^{\circ} \mathrm{C}$ and after this temperature it starts decomposing. In PANA-Zn the first weight loss observed up to $200.24^{\circ} \mathrm{C}$ is due to loss of moisture and the removal of dopants and the weight loss after $295.04^{\circ} \mathrm{C}$ corresponds to the decomposition of the polymer. In PANA-Mg the first weight loss observed up to $204.18^{\circ} \mathrm{C}$ is due to loss of moisture and the removal of dopants and the weight loss after $296.26^{\circ} \mathrm{C}$ corresponds to the decomposition of the polymer.

\subsection{TEM}

TEM as in Figure 11 shows a light coloured crystalline like structure as in PANA, when iron is introduced it shows both dark (metal) and light coloured region (polymer) tightly bounded crystalline with sponge like structure, when zinc is incorporated there is more darker granular structure indicating that more of zinc is incorporated when compared to iron. Magnesium used nanocomposites shows sponge covered granular like structure.

\section{Conclusion}

Chemical Synthesis of PANA, PANA-Fe, PANA-Zn and 

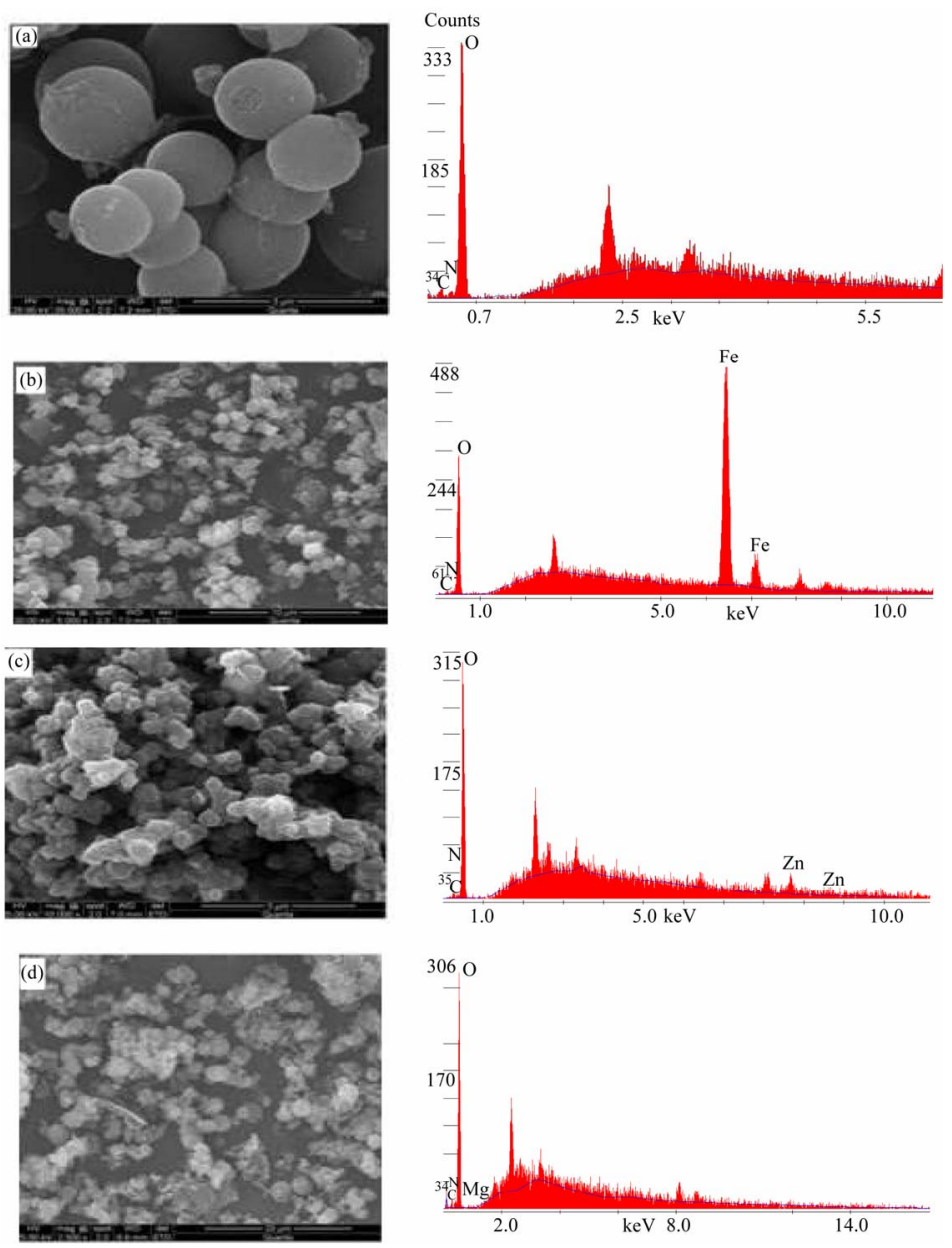

Figure 9. SEM photograph and EDAX behaviour of (a) PANA; (b) PANA-Fe; (c) PANA-Zn; (d) PANA-Mg.
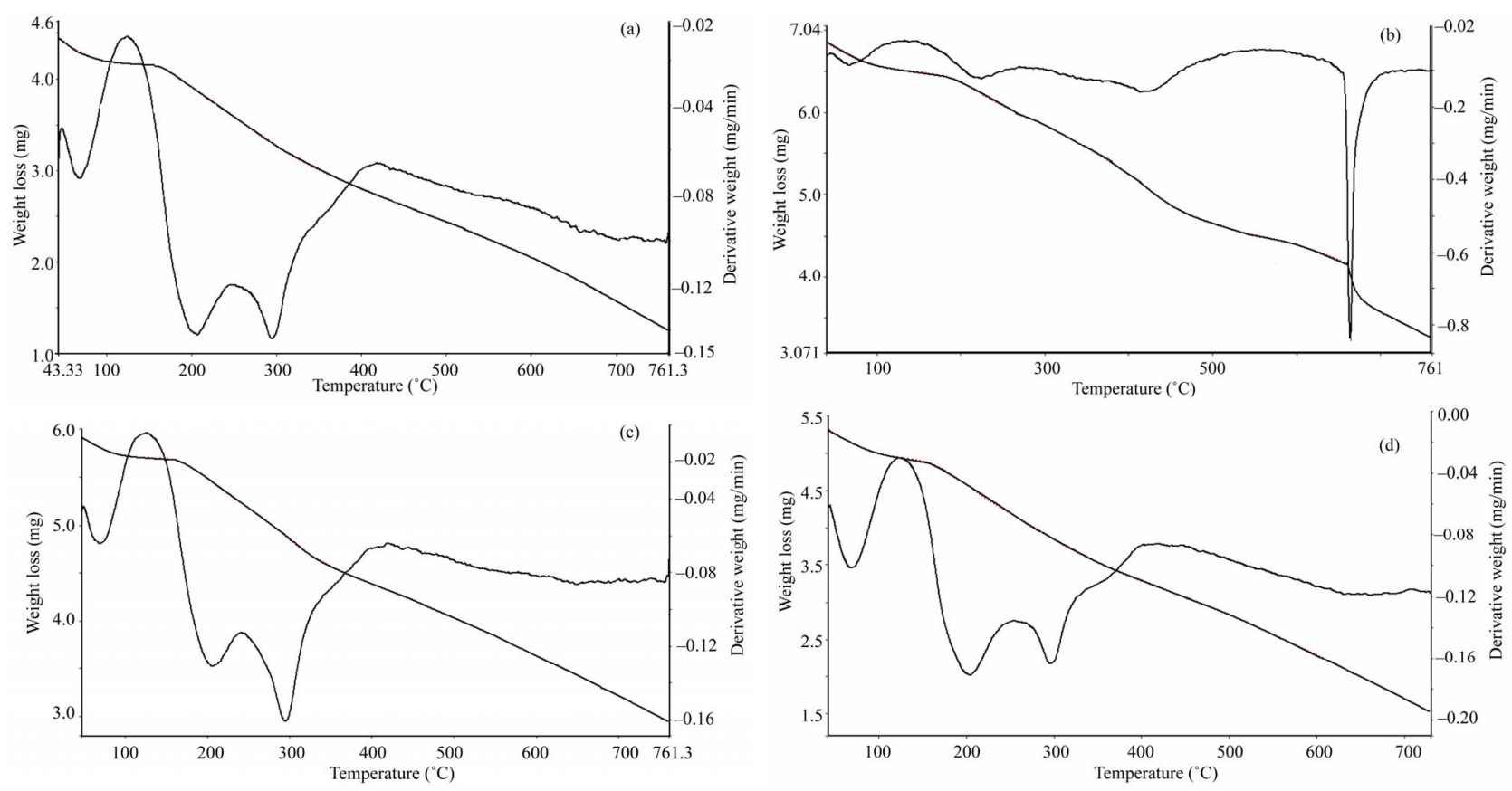

Figure 10. TGA/DTA curves of (a) PANA; (b) PANA-Fe; (c) PANA-Zn; (d) PANA-Mg. 

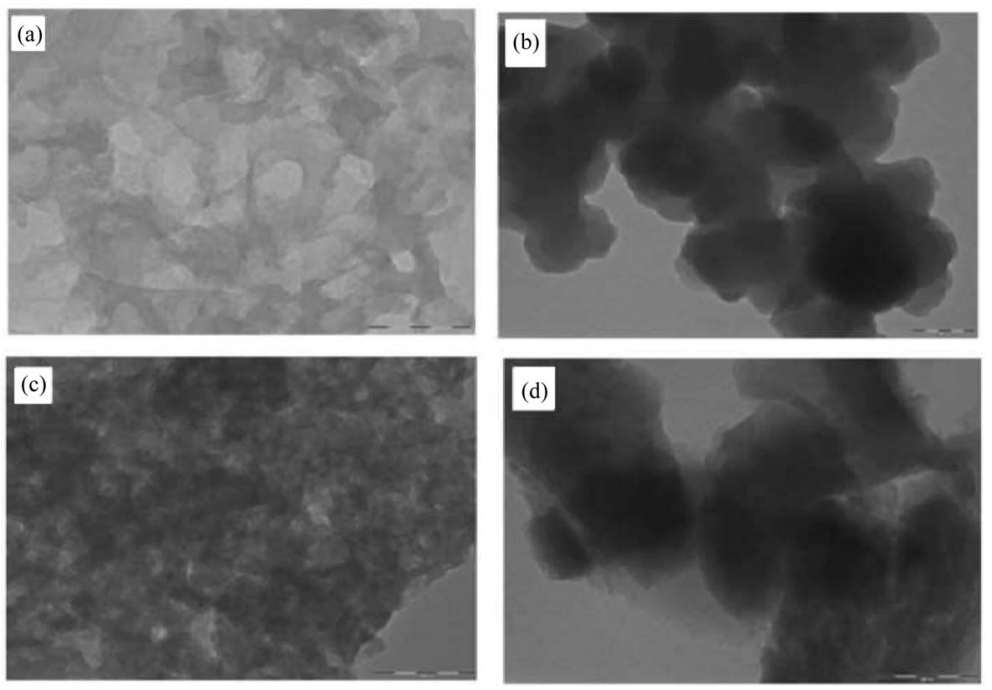

Figure 11. TEM images of (a) PANA; (b) PANA-Fe; (c) PANA-Zn; (d) PANA-Mg.

PANA-Mg were successfully carried out. The characterization of the chemically synthesized nano composites was done by using UV-Vis and FTIR studies. EIS and polarization studies agreed very well indicating PANA$\mathrm{Zn}$ and PANA-Fe act as very good anti corrosive agents for SS. CV studies revealed an adherent film on GC electrode. SEM studies show a mixed granular morphology in the case of $\mathrm{Zn}$ and $\mathrm{Mg}$ introduced polymer nano composites. Thus the chemically prepared polymer metal nano composites especially the PANA-Zn and PANA-Fe can be used as an anti corrosive pigment for paints.

\section{Acknowledgements}

The authors are extremely grateful to DST (FAST TRACK and FIST) New Delhi, INDIA for using CHI Electrochemical workstation and Jasco UV-VIS Spectrophotometer. One of the author Irudaya Antonat Sophia thanks to TNSCST for financial assistance provided for this work.

\section{REFERENCES}

[1] D. W. DeBerry, "Modification of the Electrochemical and Corrosion Behaviour of Stainless Steel with an Electroactive Coating," Journal of the Electrochemical Society, Vol. 132, No. 5, 1985, pp. 1022-1026. doi:10.1149/1.2114008

[2] R. Racicot, R. Brown and S. C. Yang, "Corrosion Protection of Aluminum Alloys by Double-Strand Polyaniline," Synthetic Metals, Vol. 85, No. 1-3, 1997, pp. 1263-1264. doi:10.1016/S0379-6779(97)80232-9

[3] P. J. Kinlen, D. S. Silverman and C. R. Jeffreys, "Corrosion Protection Using Polyaniline Coating Formulations," Synthetic Metals, Vol. 85, No. 1-3, 1997, pp. 1327-1332. doi:10.1016/S0379-6779(97)80257-3

[4] A. A. Hermas, M. Nakayama and K. Ogura, "Enrichment of Chromium-Content in Passive Layers on Stainless Steel Coated with Polyaniline," Electrochimica Acta, Vol. 50, No. 10, 2005, pp. 2001-2007.

doi:10.1016/j.electacta.2004.09.008

[5] D. Sazou, M. Kourouzidou and E. Pavlidou, "Potentiodynamic and Potentiostatic Deposition of Polyaniline on Stainless Steel: Electrochemical and Structural Studies for a Potential Application to Corrosion Control," Electrochimica Acta, Vol. 52, No. 13, 2007, pp. 4385-4397. doi:10.1016/j.electacta.2006.12.020

[6] B. Wessling, "Passivation of Metals by Coating with Polyaniline: Corrosion Potential Shift and Morphological Changes," Advanced Materials, Vol. 6, No. 3, 1994, pp. 226-228. doi:10.1002/adma.19940060309

[7] H. S. O. Chan, S. C. Ng, W. S. Sim, K. L. Tan and B. T. G. Tan, "Preparation and Characterization of Electrically Conducting Copolymers of Aniline and Anthranilic Acid: Evidence for Self-Doping by X-Ray Photoelectron Spectroscopy," Macromolecules, Vol. 25, No. 22, 1992, pp. 6029-6034. doi:10.1021/ma00048a026

[8] H. S. O. Chan, S. C. Ng, S. H. Seow, W. S. Sim and T. S. A. Hor, "Thermal Analysis of Electroactive Polymers Based on Aniline and Its Derivatives," Journal of Thermal Analysis and Calorimetry, Vol. 39, No. 2, 1993, pp. 177-185. doi:10.1007/BF01981730

[9] P. S. Rao and D. N. Sathyanarayana, "Synthesis of Electrically Conducting Copolymers of Aniline with o/mAmino Benzoic Acid by an Inverse Emulsion Pathway," Polymer, Vol. 43, No. 18, 2002, pp. 5051-5058. doi:10.1016/S0032-3861(02)00341-5

[10] M.-S. Wu, T.-C. Wen and A. Gopalan, "In Situ UV-Visible Spectroelectrochemical Studies on the Copolymerization of Diphenylamine with Anthranilic Acid," Materials Chemistry and Physics, Vol. 74, No. 1, 2002, pp. 58-65. doi:10.1016/S0254-0584(01)00406-0

[11] B. L. Rivas, and C. O. Sanchez, "Poly(2-) and (3-Aminobenzoic Acids) and Their Copolymers with Aniline: Synthesis, Characterization, and Properties," Journal of Ap- 
plied Polymer Science, Vol. 89, No. 10, 2003, pp. 26412648. doi:10.1002/app.12236

[12] H. Yan, H.-J. Wang, S. Adisasmito and N. Toshima, "Novel Syntheses of Poly(o-Aminobenzoic Acid) and Copolymers of $o$-Aminobenzoic Acid and Aniline as Potential Candidates for Precursor of Polyaniline," Bulletin of the Chemical Society of Japan, Vol. 69, No. 8, 1996, pp. 2395-2401. doi:10.1246/bcsj.69.2395

[13] C. Thiemann and C. M. A. Brett, "Electrosynthesis and Properties of Conducting Polymers Derived from Aminobenzoic Acids and from Aminobenzoic Acids and Aniline," Synthetic Metals, Vol. 123, No. 1, 2001, pp. 1-9. doi:10.1016/S0379-6779(00)00364-7

[14] C. M. A. Brett and C. Thiemann, "Conducting Polymers from Aminobenzoic Acids and Aminobenzenesulphonic Acids: Influence of $\mathrm{pH}$ on Electrochemical Behaviour," Journal of Electroanalytical Chemistry, Vol. 538-539, 2002, pp. 215-222. doi:10.1016/S0022-0728(02)01215-9

[15] H. J. Salavagione, D. F. Acevedo, M. C. Miras, A. J. Motheo and C. Barbero, "Comparative Study of 2-Amino and 3-Aminobenzoic Acid Copolymerization with Aniline Synthesis and Copolymer Properties," Journal of Polymer Science Part A: Polymer Chemistry, Vol. 42, No. 22, 2004, pp. 5587-5589. doi:10.1002/pola.20409

[16] M. T. Nguyen and A. F. Diaz, "Water-Soluble Poly(Aniline-co-o-Anthranilic Acid) Copolymers," Macromolecules, Vol. 28, No. 9, 1995, pp. 3411-3415. doi:10.1021/ma00113a047

[17] K. Mallick, K. Mondal, M. W. Comb and M. Scurrell, "Gas Phase Hydrogenation Reaction Using a 'Metal Nanoparticle-Polymer' Composite Catalyst," Journal of Materials Science, Vol. 43, No. 18, 2008, pp. 6289-6295. doi:10.1007/s10853-008-2892-7

[18] S. K. Shukla, M. A. Quraishi and R. Prakash, "A SelfDoped Conducting Polymer 'Polyanthranilic Acid': An
Efficient Corrosion Inhibitor for Mild Steel in Acidic Solution," Corrosion Science, Vol. 50, No. 10, 2008, pp. 2867-2872. doi:10.1016/j.corsci.2008.07.025

[19] F. Mansfeld, M. W. Kendig, and S. Tsai, "Evaluation of Corrosion Behavior of Coated Metals with AC Impedance Measurements," Corrosion, Vol. 38, No. 9, 1982, pp. 478-485.

[20] F. Bentiss, M. Traisnel and M. Lagrenee, "The Substituted 1,3,4-Oxadiazoles: A New Class of Corrosion Inhibitors of Mild Steel in Acidic Media," Corrosion Science, Vol. 42, No. 1, 2000, pp. 127-146. doi:10.1016/S0010-938X(99)00049-9

[21] S. Murlidharan, K. L. N. Phani, S. Pitchumani, S. Ravichandran and S. V. K. Iyer, "Polyamino-Benzoquinone Polymers: A New Class of Corrosion Inhibitors for Mild Steel," Journal of the Electrochemical Society, Vol. 142, No. 5, 1995, pp. 1478-1483. doi:10.1149/1.2048599

[22] J. Stejskal, M. Omastova, S. Fedorova, J. Prokes and M. Trchova, "Polyaniline and Polypyrrole Prepared in the Presence of Surfactants: A Comparative Conductivity Study," Polymer, Vol. 44, No. 5, 2003, pp. 1353-1358. doi:10.1016/S0032-3861(02)00906-0

[23] M. V. Kulkarni and A. K. Viswanath, "Comparative Studies of Chemically Synthesized Polyaniline and Poly (o-Toluidine) Doped with p-Toluene Sulphonic Acid," European Polymer Journal, Vol. 40, No. 2, 2004, pp. 379-384. doi:10.1016/j.eurpolymj.2003.10.007

[24] J. C. Michaelson, A. J. McEvoy and N. Kuramoto, "Morphology and Growth Rate of Polyaniline Films Modified by Surfactants and Polyelectrolytes," Reactive Polymers, Vol. 17, No. 2, 1992, pp. 197-206. doi:10.1016/0923-1137(92)90152-R

[25] N. Kuramoto and A. M. Genies, "Micellar Chemical Polymerization of Aniline," Synthetic Metals, Vol. 68, No. 2, 1995, pp. 191-194. doi:10.1016/0379-6779(94)02284-6 